\title{
Synthesis of cellulose graft ionic liquid using silanization reaction
}

\author{
Thi Lan Nhi Do ${ }^{1}$, Ngoc Lan Anh Do ${ }^{1}$, Minh Huy Do², Ut Dong Thach ${ }^{1, *}$
}

${ }^{1}$ Department of Polymer Chemistry, University of Science, VNU-HCM,227 Nguyen Van Cu str., District 5, Ho Chi Minh City, Vietnam

${ }^{2}$ Laboratoire de Chimie Agro-industrielle (LCA), Université de Toulouse, INRA, INPT, France

\section{Correspondence}

Ut Dong Thach, Department of Polymer Chemistry, University of Science, VNU-HCM,227 Nguyen Van Cu str., District 5, Ho Chi Minh City, Vietnam

Email: tudong@hcmus.edu.vn (U. D. T.)

\section{History}

- Received: 2018-11-29

- Accepted: 2019-04-15

- Published: 2019-06-13

DOI :

https://doi.org/10.32508/stdj.v22i2.1150

\section{Check for updates}

\section{Copyright}

(c) VNU-HCM Press. This is an openaccess article distributed under the terms of the Creative Commons Attribution 4.0 International license.

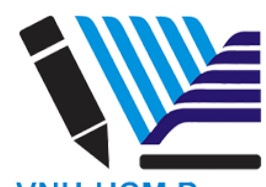

VNU-HCM Press

\begin{abstract}
Introduction: Ionic liquids (ILS) have attached many attentions due to their interesting physicochemical properties. However, ionic liquids have several disadvantages including high viscosity, difficult to purify, separate and recycle, and expensive. Therefore, supported ionic liquids (SIL) have been developed to overcome these problems. SIL based on cellulose material was conventionally synthesized by silanization reaction between ionic liquid trialkoxyl silane and hydroxyl groups on the surface of cellulose. However, low reactivity of cellulose hydroxyl groups causes the low efficiency of silanization reaction. With the aim to resolve these problems and improve the reactivity of cellulose silanization reaction, cellulose graft ionic liquid was synthesized and characterized. Methods: Cellulose graft ionic liquid (CL-IL) material was synthesized by silanization reaction. The influence of reaction condition such as IL/CL (w/W) ratio, base catalyst $\left(\mathrm{NH}_{3}\right)$ and agent coupling tetraethyl orthosilicate (TEOS) on silanization reaction was investigated. The modified CL-IL materials were characterized using FT-IR, TGA, SEM. The ion exchange properties were evaluated via batch adsorption studies to evidence the efficiency of silanization reaction of cellulose. Results: The study indicated that adding TEOS with $\mathrm{NH}_{3}$ catalyst could significantly increase the number of imidazolium groups grafted on cellulose about 75\% compared to the conventional approach. CL-IL material is an efficient anion exchange materials displaying fast kinetic adsorption and high capacity adsorption of $\mathrm{MO}$ up to $1.4 \mathrm{mmol} \mathrm{g}^{-1}$. Conclusion: High-efficiency of cellulose silanization was obtained by using coupling agent TEOS and base catalyst. Therefore, the silanization reaction can be used for synthesis divers of functional cellulose materials. This approach can be aimed for the design of cheaper and high-performance materials for catalysis, polymer composite and adsorption in water treatment and depollution of industrial wastewater.

Key words: cellulose, ionic liquid, adsorption, ion exchange
\end{abstract}

\section{INTRODUCTION}

In recent years, ionic liquids (ILs) have attached many attentions due to their interesting physicochemical properties such as low vapor pressure, thermally and chemically stable, low combustibility, and favorable interaction properties with a range of organic and inorganic compounds. ${ }^{1}$ However, ionic liquids have several disadvantages including high viscosity, difficult to purify, separate and recycle, and expensive for the use as a solvent in organic synthesis and liquid/liquid extraction. ${ }^{2}$ Supported ionic liquids (SIL) have been developed to overcome these problems. ${ }^{3,4}$ SILs are hybrid material combined the benefits of the ionic liquid characteristic with the recyclability and hydrothermal stability of support. These materials have high potential application in catalysis and separation. ${ }^{5-10}$.

Cellulose is the most abundant polymer on Earth. This biopolymer has been studied for applications in many areas such as catalysis, ${ }^{2}$ adsorption ${ }^{11-15}$ and polymer composites. ${ }^{16}$ These applications are base on surface modification of hydroxyl group on the sur- face of cellulose, for example, esterification, etherification, tosylation, and silanization. Silanes are recognized as an efficient coupling agent for mineral oxides such as $\mathrm{SiO}_{2}, \mathrm{TiO}_{2}$, and $\mathrm{Al}_{2} \mathrm{O}_{3}$. The silane coupling agents have also been of interest in applying for cellulose, since both mineral oxide and cellulose bear hydroxyl group on their surface. Several studies for surface functionalization of cellulose by silanization reaction have been reported. ${ }^{2,17}$ However, insufficient reactivity silanization is observed due to the low reactivity of hydroxyl groups of cellulose. ${ }^{17}$ Thus, the high-efficiency of cellulose silanization is desirable.

We herein report the synthesis of cellulose graft ionic liquid, a novel SIL material, using silanization reaction. The aim of this study is to improve the efficiency of cellulose silanization. It is well known that tetraethyl orthosilicate (TEOS) is higher reactive than trialkoxyl silane coupling agent. Therefore, the influences of synthesis condition such as the IL/CL $(\mathrm{w} / \mathrm{w})$ ratio, the reaction medium (neuter or basic) and the presence of tetraethyl orthosilicate (TEOS) were investigated. The modified cellulose materials 
were characterized by FT-IR, SEM, and TGA. Furthermore, ion exchange properties of methyl orange (MO) onto modified cellulose were evaluated to evidence the efficiency of silanization reaction of cellulose.

\section{METHODS}

\section{Chemicals}

Cellulose fiber (medium), (3-chloropropyl) trimethoxysilane (97\%), 1-methylimidazole (99 $\%)$, methyl orange $(85 \%$,) and tetraethyl orthosilicate (98\%) from Sigma-Aldrich were used without further purification.

\section{Preparation of ionic liquid}

The IL (1-(trimethoxysilylpropyl)-3methylimidazolium chloride) was synthesized following to previously described protocol ${ }^{2}$. In a representative procedure, (3-chloropropyl) trimethoxylsilane $(10 \mathrm{mmol})$ and 1-methylimidazole (10 mmol) were added in a well-dried $250 \mathrm{~mL}$ three-neck flask. The flask was evacuated and purged with nitrogen three times. Then, the mixture was stirred at $90{ }^{\circ} \mathrm{C}$ for $48 \mathrm{~h}$ under nitrogen atmosphere. The reaction system was then cooled at room temperature. The unreacted reactants were eliminated by thorough washing with $15 \mathrm{~mL}$ dry ethyl acetate four times. Finally, the ionic liquid product was dried under vacuum for $24 \mathrm{~h}$ at room temperature. ${ }^{1} \mathrm{H}$ NMR (500 MHz, DMSO, $\delta, \mathrm{ppm}): 0.54(\mathrm{~m}, 2 \mathrm{H})$, $1.80(\mathrm{~m}, 2 \mathrm{H}), 3.16(\mathrm{~s}, 9 \mathrm{H}), 3.91(\mathrm{~s}, 3 \mathrm{H}), 4.23(\mathrm{~m}, 2 \mathrm{H})$, 7.76-8.08 (m, 2H), 9.75 (s, 1H).

\section{Preparation of CL-IL}

The CL-IL materials were prepared using a previously described procedure with a slight modification. ${ }^{2}$ In a representative protocol, the ionic liquid was dissolved in a mixture of ethanol: water $(80: 20 \mathrm{v} / \mathrm{v})$ at a concentration of $10 \%(\mathrm{w} / \mathrm{w})$ and stirred at room temperature for $12 \mathrm{~h}$. Then, suspension of $1 \mathrm{~g}$ cellulose fiber, $5 \mathrm{mmol}$ of $\mathrm{NH}_{3}$ and $5 \mathrm{mmol}$ of TEOS were prepared in $10 \mathrm{~mL}$ of the mixture of ethanol: water $(80: 20 \mathrm{v} / \mathrm{v})$. The IL solution was added in cellulose suspension and the mixture was stirred at room temperature for $8 \mathrm{~h}$. Afterward, the solvent was eliminated by an evaporator. The obtained white solid was thermally treated at $110^{\circ} \mathrm{C}$ for $3 \mathrm{~h}$. The final material was washed thoroughly with $50 \mathrm{~mL}$ ethanol three times and dried at room temperature to eliminate unreacted products. Various modified CL-IL materials were prepared in different conditions (e.i. with or without catalyst and TEOS). The detailed name and composition of materials were shown in Table 1.

\section{Characterization}

${ }^{1} \mathrm{H}$ NMR spectroscopy was accomplished using 500 MHz Burker Avance DRX NMR Spectrometer. FTIR spectroscopy was carried out using an FT-IR Jasco 6600. TGA analysis was performed on TGA Q500 instrument. All materials were analyzed under oxygen atmosphere between 25 and $900^{\circ} \mathrm{C}$ at a heating rate of $5{ }^{\circ} \mathrm{C} / \mathrm{min}$. Scanning electron microscopy (SEM) images were conducted using a JEM-1400, $100 \mathrm{kV}$.

\section{Batch Adsorption Studies}

The adsorption isotherms of methyl orange (MO) onto CL-IL were established by shaking about $10 \mathrm{mg}$ of modified cellulose with $20 \mathrm{~mL}$ of $\mathrm{MO}$ solution in a $50 \mathrm{~mL}$ centrifuge tubes. The initial concentrations of MO were varied in the range: $0.10-2.00 \mathrm{mmol} \mathrm{L}^{-1}$. The $\mathrm{pH}$ of $\mathrm{MO}$ initial solution is 6.7. The mixtures were slowly shaken at $25{ }^{\circ} \mathrm{C}$ for $2 \mathrm{~h}$. The kinetic adsorption was studied at $\mathrm{pH} 6.7$, by shaking about 10 mg of modified cellulose and $20 \mathrm{~mL}$ of MO solution $\left(1.00 \mathrm{mmol} \mathrm{L}^{-1}\right)$ for different intervals of time in the range 2-200 min. After this time, the MO solution of the supernatant was filtered and determined by UV spectroscopy V-670 Jasco $(\lambda=464 \mathrm{~nm})$. The quantity adsorbed $\left(\mathrm{Q}_{a d s}, \mathrm{mmol} \mathrm{g}^{-1}\right)$ were determined by the following formula :

$$
Q_{a d s}=\frac{\left(C_{i}-C_{e}\right) V_{0}}{m_{s}}
$$

where $\mathrm{C}_{i}\left(\mathrm{mmol} \mathrm{L}^{-1}\right)$ and $\mathrm{C}_{e}\left(\mathrm{mmol} \mathrm{L}^{-1}\right)$ are the initial and equilibrium concentration of $\mathrm{MO}$ solution. $\mathrm{V}_{o}(\mathrm{~L})$ is the total volume of the aqueous solution and $\mathrm{m}_{s}(\mathrm{~g})$ is the mass of solid. All adsorption experiments were carried out in duplicate.

\section{RESULTS}

\section{Synthesis of CL-IL}

The modified CL-IL was synthesized by the silylation modification of cellulose (Scheme 1). The formation of CL-IL materials was confirmed using FT-IR, TGA, and SEM.

The FT-IR spectra of cellulose, ionic liquid, and modified CL-IL material were shown in Figure 1. For the CL-IL- 0.5 material, the presence of imidazolium groups on cellulose surface was confirmed by the weak adsorption band at about $1569 \mathrm{~cm}^{-1}$, corresponds for double bond $\mathrm{C}=\mathrm{N}$ of imidazolium ring. For CL-IL-TEOS material, the FT-IR spectrum demonstrates a medium absorption band at 1569 $\mathrm{cm}^{-1}$. Additionally, we observed two new weak absorption bands at 3085 and $3153 \mathrm{~cm}^{-1}$, characterize 
Table 1: Detailed of name and compositions for the preparation of modified CL-ILmaterials

\begin{tabular}{llll}
\hline Materials & $\begin{array}{l}\text { IL } \\
(\mathrm{g})\end{array}$ & $\begin{array}{l}\mathrm{NH}_{3} \\
(\mathbf{m m o l})\end{array}$ & $\begin{array}{l}\text { TEOS } \\
(\mathrm{mmol})\end{array}$ \\
CL-IL-0.1 & 0.1 & - & - \\
CL-IL-0.3 & 0.3 & - & - \\
CL-IL-0.5 & 0.5 & - & - \\
CL-IL-NH 3 & 0.5 & 5 & - \\
CL-IL-TEOS & 0.5 & - & 5 \\
CL-IL-TEOS- & 0.5 & 5 & 5 \\
NH $_{3}$ & & & \\
\hline
\end{tabular}

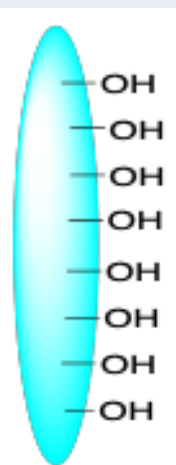

$\mathrm{CL}$

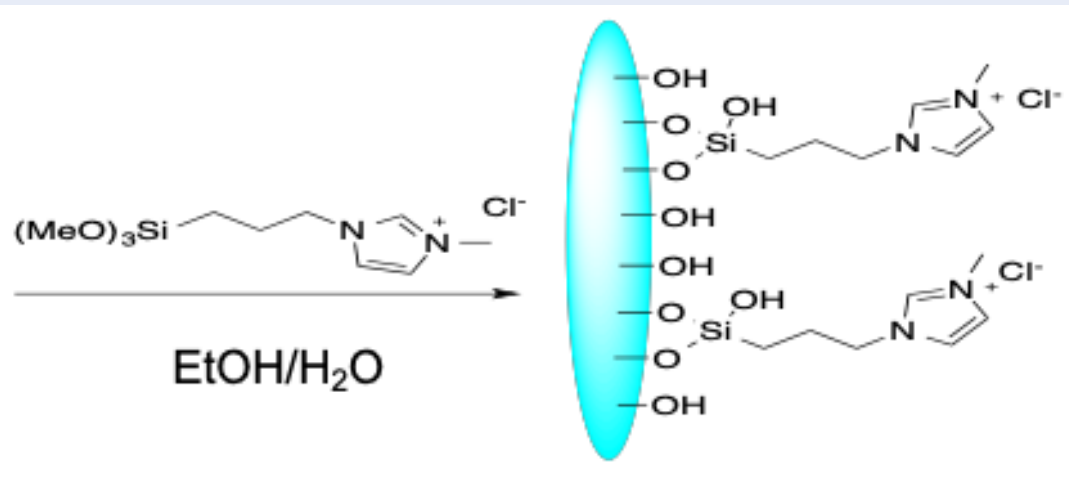

CL-IL

Scheme 1: Reaction silanization of cellulose with ionic liquid.

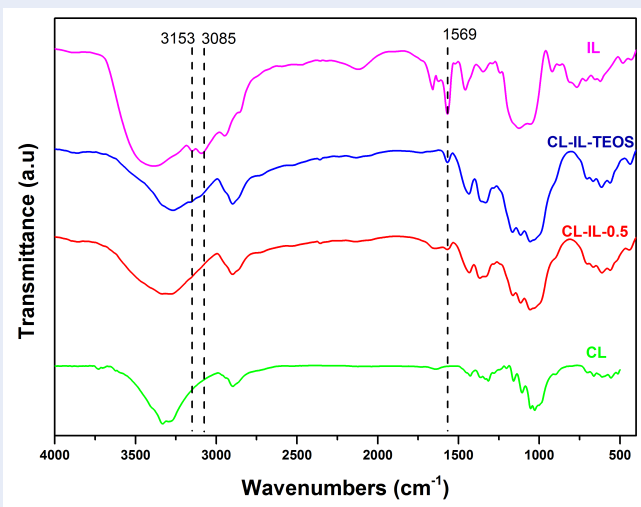

Figure 1: Comparison of FT-IR spectrum of, materials, CL: cellulose (green line); CL-IL0.5: modified cellulose with ration IL/CL(w/w) 0.5/1 (red line); modified cellulose with TEOS (blue line) and ionic liquid (pink line). 
for the stretching vibration of unsaturated $\mathrm{C}-\mathrm{H}$ bond of imidazolium ring. ${ }^{2}$

Thermal stability and composition of CL and CL-IL materials were carried out using thermogravimetric analysis (TGA). TGA plot of CL, CL-IL-0.5, and CLIL-TEOS-NH $\mathbf{N H}_{3}$ are shown in Figure 2. TGA analyses demonstrate CL and modified CL have similar thermal stability and start to decompose at about 300 ${ }^{\circ} \mathrm{C}$. The residual weight percent for CL, CL-IL-0.5, and CL-IL-TEOS are 1, 4 and 15\%, respectively. The residual weights for modified CL are related to the formation of $\mathrm{SiO}_{2}$ during the TGA analysis condition under the oxygen atmosphere.

Scanning electron microscopy (SEM) was then used to characterize the morphology of materials. The SEM images of CL-IL-0.5 and CL-IL-TEOS- $\mathbf{N H}_{3}$ are shown in Figure 3. The SEM images of ionic liquid modified cellulose without TEOS (CL-IL-0.5) showed the fiber structure of cellulose with the diameter of fiber about $20 \mu \mathrm{m}$ and a relatively homogeneous surface of the fiber. In the SEM image of modified cellulose with TEOS, we observed the formation of equant particles with the diameter about 1-6 $\mu \mathrm{m}$ on the surface of modified cellulose fiber. These particles can be referred to the formation of $\mathrm{SiO}_{2}$ particles on the surface of cellulose during the functionalized conditions.

\section{Adsorption properties}

Kinetic study. Adsorption kinetic of ion exchange material is an important parameter for the potential application in wastewater treatment. Therefore, the adsorption kinetic MO onto CL-IL was studied. The effect of contact time on quantity adsorbed of $\mathrm{MO}$ onto the representative material CL-IL-TEOS- $\mathbf{N H}_{3}$ was shown in Figure 4. The results demonstrated that kinetic adsorption of ion exchange is fast. About $90 \%$ of MO exchange is reached after $10 \mathrm{~min}$ and the saturation of ion exchange is reached after $120 \mathrm{~min}$. The detailed kinetic parameters were determined using Lagergren pseudo-first-order model ${ }^{18}$ and pseudosecond-order model ${ }^{19,20}$. The non-linear method was used to calculate the best-fit kinetic model. The calculated result of kinetic parameters is shown in Table 2 . The pseudo-second-order model is suitable to describe the kinetic adsorption of MO onto modified CL-IL material. This result suggests that the sorption process occurs via electrostatic interaction mechanism. ${ }^{21,22}$

Adsorption Isotherm of MO. The influence of $\mathrm{IL} / \mathrm{CL}(\mathrm{w} / \mathrm{w})$ ratio on the adsorption of MO onto CLIL materials was studied. The adsorption isotherms of MO on CL, CL-IL-0.1; CL-IL-0.3 and CL-IL-0.5 are shown in Figure 5a. MO adsorption capacity of $\mathrm{CL}$ is very low. While the adsorption capacity of $\mathrm{MO}$ onto modified CL-IL is $0.2,0.4$ and $0.8 \mathrm{mmol} \mathrm{g}^{-1}$ for CL-IL-0.1, CL-IL-0.3, and CL-IL-0.5, respectively. That means the adsorption capacity of MO increase with increasing of $\mathrm{IL} / \mathrm{CL}(\mathrm{w} / \mathrm{w})$ ratio. The increasing of $\mathrm{MO}$ adsorption capacity is due to the number of imidazolium groups grafted on the surface of $\mathrm{CL}$ material.

We then studied the influence of the catalysis $\mathrm{NH}_{3}$ on adsorption of MO. The material CL-IL- $\mathrm{NH}_{3}$ was synthesized in the same condition with CL-IL-0.5 with the presence of $\mathrm{NH}_{3}$. Sorption isotherms of $\mathrm{MO}$ on CL-IL-0.5 and CL-IL-NH 3 were shown in Figure 5b. The results demonstrated that two modified cellulose materials showed similar adsorption isotherm.

The influence of TEOS on MO adsorption capacity was finally studied. The modified CL-IL materials synthesized with or without TEOS were used for this study. Figure $5 \mathrm{c}$ shows the sorption isotherms of $\mathrm{MO}$ on CL-IL-0.5; CL-IL-TEOS and CL-IL-TEOS-NH . $_{3}$ We observed that the CL-IL synthesized in the presence of agent coupling TEOS have a higher adsorption capacity than CL-IL synthesized without TEOS. Interestingly, CL-IL material synthesized in the presence of TEOS and $\mathrm{NH}_{3}$ shows the best adsorption properties with quantity adsorbed up to $1.4 \mathrm{mmol} \mathrm{g}^{-1}$. That means the formation of CL-IL materials is favorable with the presence of agent coupling TEOS and base $\mathrm{NH}_{3}$.

\section{DISCUSSION}

The synthesis condition such as ratio ionic liquid/cellulose $(\mathrm{w} / \mathrm{w})$, catalyst $\left(\mathrm{NH}_{3}\right)$, and adding TEOS defined considerable influent on the cellulose silanization reaction. The number of ionic groups graft on cellulose increased with increasing the ration ionic liquid/cellulose (w/w). The maximum number of imidazolium groups grafted is $0.8 \mathrm{mmol}$ per gram cellulose with the ratio ionic liquid/cellulose $(w / w)$ of $0.5 / 1$. However, the base catalysis $\left(\mathrm{NH}_{3}\right)$ has no influence on the silanization reaction. Interestingly, the addition of TEOS defined a considerable impact on the silanization reaction. Adding only TEOS in the reaction improved about $25 \%$ of number imidazolium groups grafted on cellulose $\left(1.0 \mathrm{mmol}^{-1}\right)$. Additionally, the silanization reaction was carried out with TEOS and base catalysis $\mathrm{NH}_{3}$ improved about $75 \%$ of number imidazolium group grafted on cellulose $\left(1.4 \mathrm{mmol}^{-1}\right)$. Adding TEOS and base catalysis favored the formation of $\mathrm{SiO}_{2}$ particle on the surface of cellulose, and therefore, improve the silanization coupling between cellulose and silane coupling agent. 


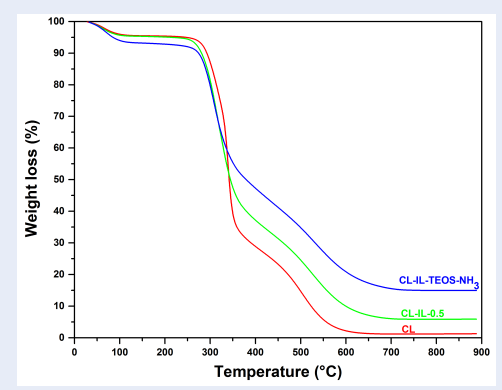

Figure 2: TGA plots of materials, CL-cellulose (red line); CI-IL-0.5: modified cellulose with ration IL/CL(w/w) $0.5 / 1$ (green line) and CL-IL-TEOS- $\mathrm{NH}_{3}$ : modified cellulose with $\mathrm{TEOS}$ and $\mathrm{NH}_{3}$ (blue line)

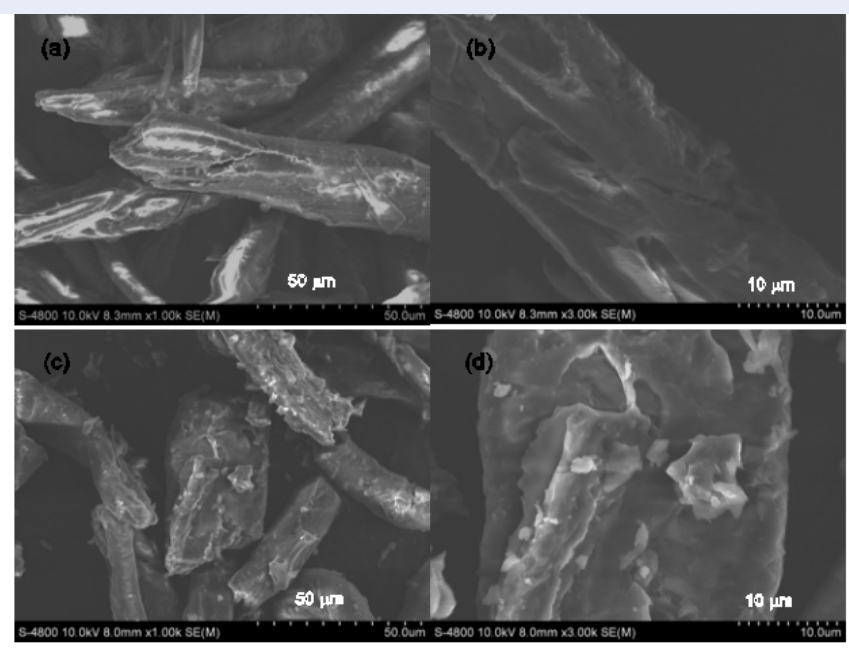

Figure 3: SEM images of materials at different magnification, (a), (b) : Cl-IL-0.5, modified cellulose with ration $\mathrm{IL} / \mathrm{CL}(\mathrm{w} / \mathrm{w}) 0.5 / 1$ and (c), (d) : CL-IL-TEOS-NH $\mathrm{NH}_{3}$, modified cellulose with TEOS and $\mathrm{NH}_{3}$

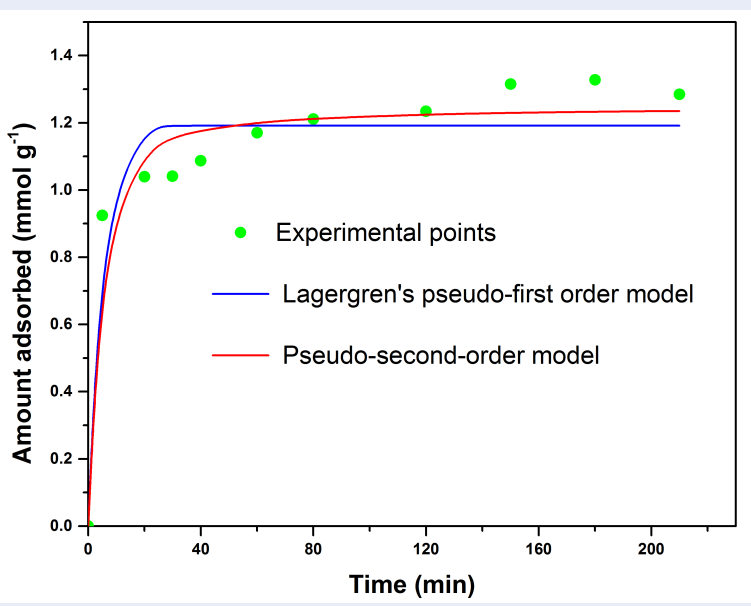

Figure 4: Effect of contact time on adsorption of $\mathrm{MO}$ onto $\mathrm{CL}-\mathrm{IL}-\mathrm{TEOS}-\mathrm{NH}_{3}$ materials (green points), the fitted data from the Lagergren pseudo-first-order (blue line) and pseudo-second-order model (red line) calculated using the non-linear method 
Table 2: Adsorption kinetic properties of MO onto CL-IL-TEOS-NH

\begin{tabular}{lllllll}
\hline & \multicolumn{2}{c}{ Lagergren pseudo-first-order model } & \multicolumn{4}{c}{ Pseudo-second-order model } \\
Material & $\mathrm{Q}_{\text {e.cal. }}\left(\mathrm{mmol} \mathrm{g}^{-1}\right)$ & $\mathrm{K}_{1}\left(\mathrm{~min}^{-1}\right)$ & $\mathrm{R}_{1}{ }^{2}$ & $\mathrm{Q}_{\text {e.cal. }}\left(\mathrm{mmol} \mathrm{g}^{-1}\right)$ & $\begin{array}{l}\mathrm{K}_{2} \\
\left(\mathrm{~min}^{-1}\right)\end{array}$ & $\mathrm{R}_{2}{ }^{2}$ \\
& & & & & 0.3314 & 0.9389 \\
$\begin{array}{l}\mathrm{CL}-\mathrm{IL}-\mathrm{TEOS}- \\
\mathrm{NH}_{3}\end{array}$ & 1.1912 & 0.2933 & 0.8833 & 1.2494 & & \\
\hline
\end{tabular}
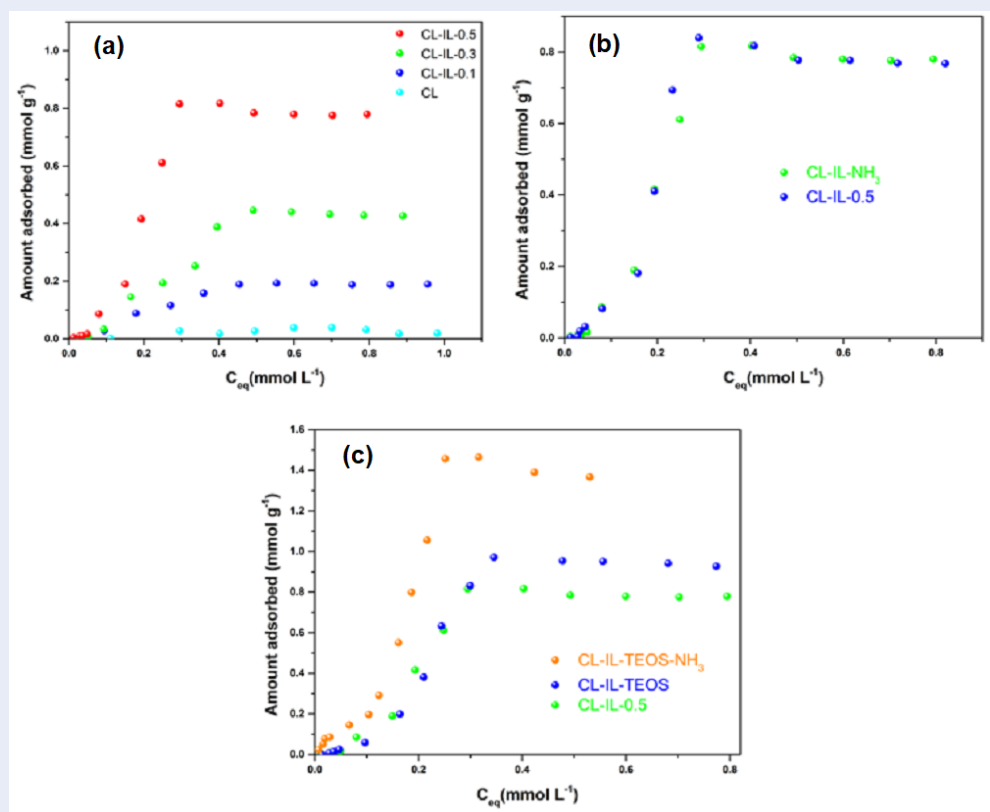

Figure 5: Comparison of sorption isotherms of MO onto the CL-IL materials: (a) CL; CL-IL-0.1; CL-IL-0.3 and CL-IL-0.5; (b) CL-IL-0.5 and CL-IL-NH 3 and (c) CL-IL-0.5; CL-IL-TEOS and CL-IL-TEOS-NH

\section{CONCLUSIONS}

CL-IL materials were successfully synthesized by silanization reaction of surface hydroxyl groups on cellulose and trimethoxylsilane groups of the ionic liquid. The influence of reaction condition on the formation of CL-IL materials was investigated. Highefficiency modification of cellulose surface was obtained with the presence of agent coupling TEOS and $\mathrm{NH}_{3}$. CL-IL materials are efficiency ion exchange material with fast sorption kinetic and high sorption capacity up to $1.4 \mathrm{mmol} \mathrm{g}^{-1}$. Coupling agent TEOS displayed as a promising candidate for the silanization reaction of cellulose. This approach can be used for synthesis divers of functional cellulose materials, which can be aimed for the design of cheaper and high-efficient materials for catalysis, polymer composite, and adsorption in water treatment and depollution of industrial wastewater.

\section{ABBREVIATIONS}

CL: Cellulose

FT-IR: Fourier-transform infrared spectroscopy

IL: Ionic liquid

MO: Methyl orange

NMR: Nuclear magnetic resonance

SEM: Scanning electron microscopy

SIL: Supported ionic liquid

TEOS: Tetraethyl orthosilicate

TGA: Thermogravimetric analysis

\section{COMPETING INTERESTS}

The authors declare no competing interests.

\section{AUTHORS' CONTRIBUTIONS}

Ut Dong Thach designed the study and wrote the paper. Thi Lan Nhi Do and Ngoc Lan Anh Do conducted the experiments. Minh Huy Do helped to revise the manuscript. 


\section{ACKNOWLEDGMENTS}

The authors thank University of Science, Vietnam National University Ho Chi Minh City (VNU-HCM) for the funding under grant number T2017-17.

\section{REFERENCES}

1. Plechkova NV, Seddon KR. Applications of ionic liquids in the chemical industry. Chem Soc Rev [Internet]. 2008;37(1):12350. Available from: https://doi.org/10.1039/B006677J.

2. Pourjavadi A, Habibi Z. Gold nanoparticles supported on ionic liquid-modified cellulose as an efficient and recyclable catalyst for the oxidation of alcohols to aldehydes/ketones and reduction of nitroarenes. Appl Organomet Chem [Internet]. 2017;11(11):1-8. Available from: https://doi.org/10.1002/aoc. 3783.

3. DeCastro C, Sauvage E, Valkenberg MH, Hölderich WF. Immobilised ionic liquids as Lewis acid catalysts for the alkylation of aromatic compounds with dodecene. J Catal [Internet]. 2000;196(1):86-94. Available from: https://doi.org/10.1006/ jcat.2000.3004.

4. Mehnert CP, Cook RA, Dispenziere NC, Afeworki M. Supported Ionic Liquid Catalysis - A New Concept for Homogeneous Hydroformylation. J Am Chem Soc [Internet]. 2002;124:12932-3. Available from: https://pubs.acs.org/doi/10.1021/ja0279242.

5. Thach UD, Prelot B, Pellet-Rostaing S, Zajac J, Hesemann P. Surface Properties and Chemical Constitution as Crucial Parameters for the Sorption Properties of lonosilicas: The Case of Chromate Adsorption. ACS Appl Nano Mater [Internet]. 2018;25(1):2076-87. Available from: http://pubs.acs.org/doi/ 10.1021/acsanm.8b00020.

6. Braun M, Thach UD, Prelot B, Hesemann P, Esposito D. Pd@ionosilica as heterogeneous hydrogenation catalyst for continuous flow reductive upgrade of cinnamaldehyde. J Chem Technol Biotechnol [Internet]. 2017;92(9):2229-35. Available from: https://doi.org/10.1002/jctb.5278.

7. Thach UD, Prelot B, Hesemann P. Tailoring ionosilicas for the efficient adsorption of $\mathrm{p}$ - aminosalicylate. Sep Purif Technol. Sep Purif Technol [Internet]. 2017;196:217-23. Available from: https://doi.org/10.1016/j.seppur.2017.07.067.

8. Thach UD, Trens P, Prelot B, Zajac J, Hesemann P. Tuning the interfacial properties of mesoporous ionosilicas: Effect of cationic precursor and counter anion. J Phys Chem C [Internet]. 2016;120(48):27412-21. Available from: https://pubs.acs. org/doi/10.1021/acs.jpcc.6b09457.

9. Thach UD, Hesemann P, Yang G, Geneste A, Caër SL, Prelot B. lonosilicas as efficient sorbents for anionic contaminants: Radiolytic stability and ion capacity. J Colloid Interface Sci [Internet]. 2016;482:233-9. Available from: http://dx.doi.org/10. 1016/j.jcis.2016.07.069.
10. Bouchal R, Miletto I, Thach UD, Prelot B, Berlier G, Hesemann $P$. Ionosilicas as efficient adsorbents for the separation of diclofenac and sulindac from aqueous media. New J Chem [Internet]. 2016;40(9):7620-6. Available from: https://pubs.rsc. org/en/content/articlelanding/2016/nj/c6nj01473a.

11. Huang $X$, Zhan X, Wen $C, X u$ F, Luo L. Amino-functionalized magnetic bacterial cellulose/activated carbon composite for $\mathrm{Pb} 2+$ and methyl orange sorption from aqueous solution. J Mater Sci Technol [Internet]. 2018;34(5):855-63. Available from: http://dx.doi.org/10.1016/j.jmst.2017.03.013.

12. Aliabadi HM, Saberikhah E, Pirbazari AE, Khakpour R, Alipour H. Triethoxysilylpropylamine modified alkali treated wheat straw: An efficient adsorbent for methyl orange adsorption. Cellul Chem Technol. 2018;52:1-2.

13. Zhang $\mathrm{H}$, Luan $\mathrm{Q}$, Tang $\mathrm{H}$, Huang $\mathrm{F}$, Zheng $\mathrm{M}$, Deng $\mathrm{Q}$, et al. Removal of methyl orange from aqueous solutions by adsorption on cellulose hydrogel assisted with $\mathrm{Fe} 2 \mathrm{O} 3$ nanoparticles. Cellulose. 2017;24(2):903-14.

14. Zhang G, Yi L, Deng H, Sun P. Dyes adsorption using a synthetic carboxymethyl cellulose-acrylic acid adsorbent. J Environ Sci (China) [Internet]. 2014;26(5):1203-11. Available from: http://dx.doi.org/10.1016/S1001-0742(13)60513-6.

15. Annadurai G, Juang RS, Lee D. Use of cellulose - based wastes for adsorption of dyes from aqueous solutions. J Hazard Mater. 2002;92(3):263-74.

16. Xie $Y$, Hill CAS, Xiao Z, Militz H, Mai C. Silane coupling agents used for natural fiber/polymer composites: A review. Compos Part A Appl Sci Manuf [Internet]. 2010;41(7):806-19. Available from: http://dx.doi.org/10.1016/j.compositesa.2010.03.005.

17. Abdelmouleh $M$, Boufi $S$, Salah AB, Belgacem MN, Gandini $A$. Interaction of silane coupling agents with cellulose. Langmuir. 2002;18(8):3203-8.

18. Lagergren S. Zur Theorie der Sogenannten Adsorption Gelöster Stoffe. Sven Vetenskapsakad Handl. 1898;24:1-39.

19. Da'na E, Silva ND, Sayari A. Adsorption of copper on aminefunctionalized SBA-15 prepared by co-condensation: Kinetics properties. Chem Eng J [Internet]. 2011;166:454-459. Available from: https://doi.org/10.1016/j.cej.2010.11.017.

20. Ho YS, McKay G. Pseudo-second order model for sorption processes. Process Biochem [Internet]. 1999;34:451-465. Available from: https://doi.org/10.1016/S0032-9592.

21. Prelot B, Ayed I, Marchandeau F, Zajac J. On the real performance of cation exchange resins in wastewater treatment under conditions of cation competition: the case of heavy metal pollution. Environ Sci Pollut Res [Internet]. 2014;21:93349343. Available from: https://dx.doi.org/10.1007/s11356-0142862-3.

22. Mohan D, Singh KP, Singh VK. Removal of hexavalent chromium from aqueous solution using low-cost activated carbons derived from agricultural waste materials and activated carbon fabric cloth. Ind Eng Chem Res [Internet]. 2005;44:1027-42. Available from: https://pubs.acs.org/doi/ abs/10.1021/ie0400898. 